\title{
The Influence of Fetal Head Circumference and Fetal Weight Assessed by Intrapartum Ultrasound on Labor Outcome
}

\author{
Isameel Talaat Elgarhy, Noha Mohamed Sabry, Hossam Mohamed Mohamed Abdelkader \\ Department of Obstetrics and Gynecology, Faculty of Medicine, Al-Azhar University \\ *Corresponding author: Hossam Mohamed Mohamed Abdelkader, Mobile: (+20)01003377224; Email: \\ dr.hossam201010@gmail.com
}

\begin{abstract}
Background: birth represents one of the most important of all the experiences of the human race. Despite the complexity and sophistication of modern obstetrics, it is important to remember the simple objective of every pregnancy, namely the delivery of healthy baby to healthy mother. During the last decade, assessment of prolonged second stage has been incorporated into the standard routine antepartum and intrapartum evaluation of labor. Objective: The aim of the present study was to determine if fetal head circumference and fetal weight could predict the rate of caesarian section and vaginal deliveries in primigravidas women in labor.

Patients and methods: The study is a prospective cohort study that was conducted at Alexandria Police Hospital maternity labor ward from April 2018 to December 2018. One hundred pregnant parturient admitted to the labor ward of Alexandria Police Hospital for delivery were participated in this study according to specific inclusion criteria. Results: The present study assessed ultrasonographically the head circumference and fetal weight as predictive values on labor outcome. The receiver operator curve (ROC) showed that these were good predictors of mode of delivery (sensitivity of $85 \%$ and specificity of $92.6 \%$ ).

Conclusion: The numerical data have a significant relation between intra partum head circumference and fetal weight relative to maternal pelvic diameter and the incidence of primary caesarian section, maternal and fetal complications. So measurement of intrapartum head circumference and fetal weight are good predictors of labor outcome.
\end{abstract}

Keywords: Fetal Head Circumference, Fetal Weight, Intrapartum Ultrasound

\section{INTRODUCTION}

Birth represents one of the most important of all the experiences of the human kind. Despite the complexity and sophistication of modern obstetrics it is important to remember the simple objective of every pregnancy, namely the delivery of a healthy baby to a healthy mother. The fullest possible understanding of the birth process, its perturbations and appropriate management policies is central to that objective ${ }^{(\mathbf{1})}$.

One of these complexities is prolonged labour, operative delivery procedures arising from prolonged labor increase maternal morbidity, fetal morbidity, and the cost of care. Cephalopelvic disproportion (CPD), due to narrow maternal pelvic diameter relative to fetal head circumference (FHC) or large FHC relative to maternal pelvic diameter, is the main cause of prolonged labor ${ }^{(2)}$.

Maternal risks include birth canal and pelvic floor injuries, increased rate of operative vaginal and caesarean deliveries, and postpartum hemorrhage ${ }^{(3)}$. Birth weight of an infant is the single most important determinant of newborn survival (4). Limiting the potential complications associated with the birth of excessively large fetuses requires that accurate estimation of fetal weight occurs before decision to deliver is made ${ }^{(5)}$.

The two main methods for predicting birth weight in current obstetrics are clinical and ultrasonographic methods ${ }^{(6)}$. Increasing attention is being paid to the accuracy of using various ultrasound measurements in estimating fetal head circumference and fetal weight. Ultrasound could be useful for decreasing the number of $\mathrm{C}$-sections performed defensively by obstetricians who wish to avoid the possibility of a complicated delivery ${ }^{(7)}$.

\section{AIM OF THE WORK}

The aim of the present study is to determine if fetal head circumference and fetal weight could predict the rate of caesarian section and operative vaginal deliveries in nulliparous women in labor.

\section{PATIENTS AND METHODS}

Design and Settings: The study is a prospective cohort study that was conducted at Alexandria Police Hospital maternity labor ward from April 2018 to December 2018. The study was approved by the Ethics Board of Al-Azhar University.

Methods: One hundred pregnant parturient admitted to the labor ward of Alexandria police Hospital for delivery were subjected to the following inclusion criteria of the study.

Inclusion criteria:

- Maternal age between 20 to 30 years old.

- All parturients were primigravidas.

- Normal singleton pregnancies. 
- Cephalic presentation in labour with gestational age between 38 to 40 weeks.

- No congenital fetal abnormalities detected by U/S. Exclusion criteria:

- Maternal age less than 20 and more than 30 years old.

- Multigravidas and multiple pregnancies.

- Malpresented foetuses.

- Gestational age less than 38 weeks.

- Women with uncertain gestational age, intrauterine fetal deaths and fetal anomalies were excluded.

- Those who had elective or emergency caesarean section for indications such as antepartum haemorrhage, preeclampsia/eclampsia, poorly controlled diabetes mellitus and other medical disorders of pregnancy prior to onset of labour were also excluded.

The following was applied to all women included in the current study:

- Evaluation of full obstetric history.

- General examination as regard general condition and vital data.

- Abdominal examination as regard fundal level, fetal position.

- Fetal heart rate monitoring by CTG.

- Vaginal examination as regard cervical dilatation, effacement and state of membranes.

- According to the hospital standards in the labor room, patients were managed.

All women included in the current study were examined by trans-abdominal ultra-sound using LOGIC A5 (define manufacturer and country of origin) set in labor ward to measure the fetal head circumference and fetal weight.

Fetal weight was estimated by measuring 4 biometric indices which are abdominal circumference (AC) biparital diameter (BPD) femur length (FL) and head circumference $(\mathrm{HC}){ }^{(8)}$.

BPD was measured from proximal echo of the fetal skull to the proximal edge of the deep border (outer-inner) at the level of the cavum septum pellucidum. The $\mathrm{HC}$ was measured as an ellipse around the perimeter of the fetal skull ${ }^{(9)}$.

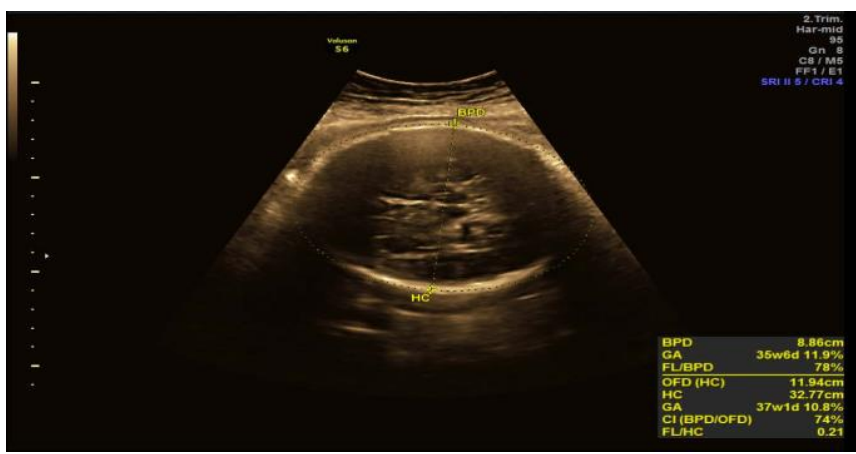

Fig. (1): Biparital diameter and head circumference
The AC was measured in the transverse plane of the fetal abdomen at the level of the umbilical vein in the anterior third and the stomach bubble in the same plane, measurements were taken around the perimeter ${ }^{(9)}$.

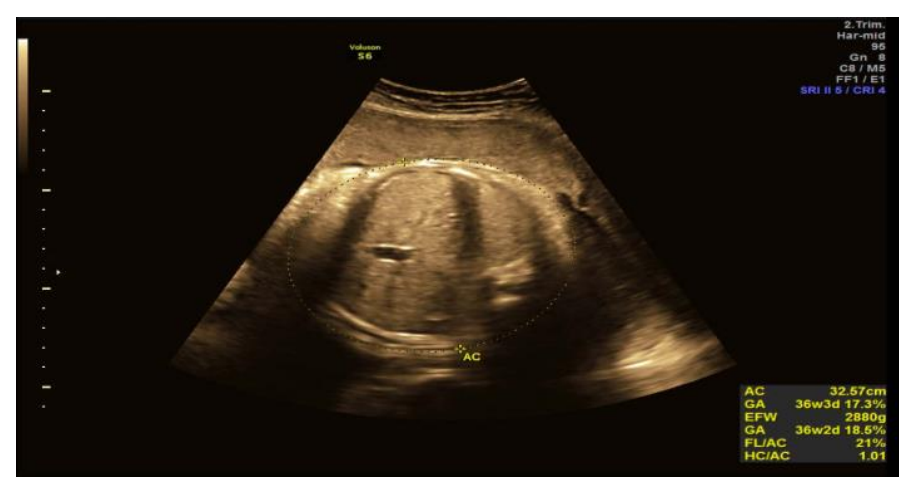

Fig. (2): Abdominal circumference

The FL was measured in a view where the full femoral diaphysis was seen and was taken from one end of the diaphysis to the other, not including the distal femoral epiphysis ${ }^{(9)}$.

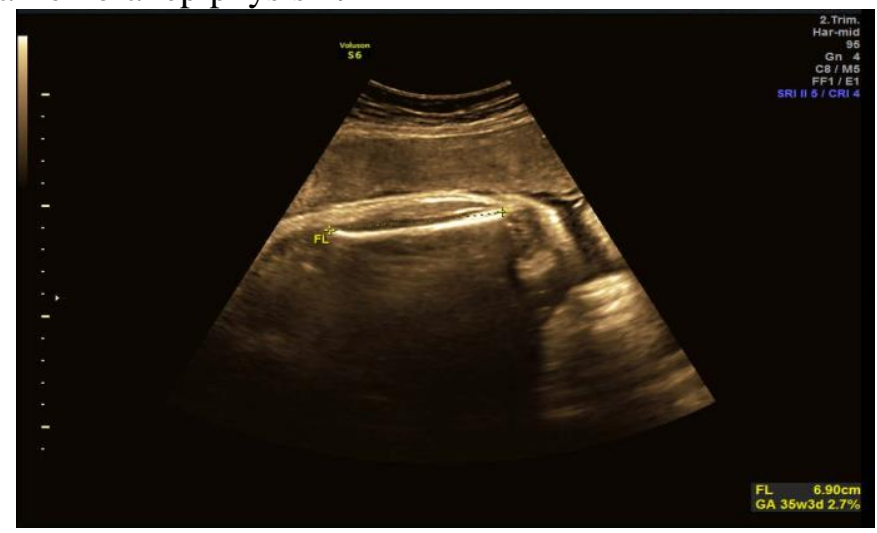

Fig. (3): Femur length

Then post-natal fetal head circumference and fetal weight was measured and recorded.

Outcome was classified into:

- Primary outcome:

1) Vaginal delivery.

- Secondary outcomes:

1) Ccaesarean section.

2) Maternal and fetal complications result as a direct effect to the mode of delivery.

Maternal complications: Birth canal and pelvic floor injuries, instrumental and operative vaginal deliveries, traumatic and atonic post partum haemorrhage.

Neonatal complications: Birth asphyxia (decrease fetal oxygen supply during labour that requires postpartum neonatal assisted ventilation), shoulder dystocia, birth injuries (e.g. caput succedaneum, cephalic hematoma, brachial plexus palsy), metabolic disorders (e.g. metabolic acidosis), 
meconium aspiration syndrome, and still birth. Finally assessing the critical range of fetal head circumference in $\mathrm{cm}$ and fetal weight in grams at which these women were subjected to complicated labour.

Sample Size Justification: Sample size was calculated using PASS program, setting the type-1 error $(\alpha)$ at 0.05 and the power $(1-\beta)$ at 0.7 . Results from a previous study by Mujugira et al ${ }^{(\mathbf{1 0 )}}$ showed that it was estimated that $40 \%$ of large fetal head circumference babies were delivered by CS while only $22 \%$ of average head circumference babies were delivered by CS. Calculation according to these values produced a minimalsample size of 200 cases. Data Management and Analysis: The collected data was revised, coded, tabulated and introduced to a PC using Statistical package for Social Science (SPSS 15.0.1 for windows; SPSS Inc, Chicago, IL, 2001). Data was presented as mean and standard deviation $( \pm S D)$ for quantitative parametric data, and Median and Interquartile range for quantitative non parametric data. Frequency and percentage was used for presenting qualitative data. Suitable analysis was done according to the type of data obtained. Student t-test or Mann Whitney test was used to analyze quantitative data while chi square test and fisher exact test was used to analyze qualitative data.

Probability (P-value)

P-value $<0.05$ was considered significant.

P-value $<0.001$ was considered as highly significant. $\mathrm{P}$-value $>0.05$ was considered insignificant.

\section{RESULTS}

This study was carried out on 100 nulliparous women at Alexandria Police Hospital.

Table (1): Clinico-demographic data of the studied women group

\begin{tabular}{|l|l|l|c|c|}
\hline & Min. & Max. & Mean & S.D. \\
\hline Age (year) & 21.00 & 30.00 & 25.3600 & 2.96621 \\
GA (week) & 38.00 & 40.00 & 38.9900 & .82260 \\
BMI & 21.10 & 28.00 & 24.1690 & 1.88287 \\
\hline
\end{tabular}

Table (1), show the demographic and clinical data of the studied women, the age was ranged from 21-30 years with a mean of $25.36 \pm 2.96$ years, the gestational age was ranged from 38.0-40.0 weeks with a mean of $38.99 \pm 0.822$, and the body mass index was ranged from $21.1-28.0$ with a mean of $24.16 \pm 1.88$.

Table (2): Fetal measurements and outcome

\begin{tabular}{|c|c|c|c|c|}
\hline & Min. & Max. & Mean & S.D. \\
\hline Intrapartum Head circumference $(\mathrm{cm})$ & 31.00 & 36.00 & 33.61 & 1.46 \\
\hline estimated fetal weight & 1800.00 & 4000.00 & 2845.70 & 639.82 \\
\hline Postpartum head circumference $(\mathrm{cm})$ & 31.70 & 36.80 & 34.35 & 1.50 \\
\hline fetal weight $(\mathrm{gm})$ & 1890.00 & 4200.00 & 2988.23 & 671.83 \\
\hline APGAR score $1 \mathrm{~min}$ & 5.00 & 9.00 & 7.05 & 1.38 \\
\hline APGAR score 5 min. & 7.00 & 10.00 & 8.58 & 1.18 \\
\hline
\end{tabular}

Table (2) show the fetal measurements, the intrapartum head circumference was ranged from $31.0-36.0 \mathrm{~cm}$ with a mean of $33.61 \pm 1.46 \mathrm{~cm}$, the estimated fetal weight was ranged from 1800-4000 gm, with a mean of $2845.7 \pm 639.82 \mathrm{gm}$, post-partum head circumference was $31.7-36.80$ with a mean of $34.35 \pm 1.50 \mathrm{~cm}$, the fetal weight was ranged from 1890-4200 gm with a mean of 2988.23 $\pm 671.8(\mathrm{gm})$. The APGAR score at 1 min. was ranged from 5.0-9.0 with a mean value of 7.05 \pm 1.38 , the APGAR score 5 min was ranged from 7.0-10 with a mean of $8.58 \pm 1.18$.

Table (3): Mode of delivery in the studied group

\begin{tabular}{||l|c|c||}
\hline & Frequency & Percent \\
\hline Normal vaginal delivery & 68 & 68.0 \\
\hline C.S. & 32 & 32.0 \\
\hline Total & 100 & 100.0 \\
\hline
\end{tabular}

Table (3) shows the mode of delivery in the studied group, it was found that the C.S. was done in $32.0 \%$ of the cases. 
Table (4): Maternal complications in the studied patients group

\begin{tabular}{||l|l|c||}
\hline No & quency & Percent \\
\hline $\begin{array}{l}\text { Birth canal or } \\
\text { pelvic floor } \\
\text { injuries }\end{array}$ & 49 & 25.0 \\
\hline $\begin{array}{l}\text { post partum } \\
\text { hemorrhage }\end{array}$ & 4 & 49.0 \\
\hline $\begin{array}{l}\text { operative } \\
\text { traumatic }\end{array}$ & 22 & 22.0 \\
\hline Total & 100 & 100.0 \\
\hline
\end{tabular}

Table (4) show the maternal complications, $25.0 \%$ of cases without complication, while the other $75.0 \%$ had complications as shown in table (4).
Table (5): Neonatal complications in the studied fetus

\begin{tabular}{||l|c|l||}
\hline & requency & ercent \\
\hline No & 57 & 57.0 \\
\hline Birth asphyxia & 13 & 13.0 \\
\hline Birth injuries & 12 & 12.0 \\
\hline $\begin{array}{l}\text { metabolic } \\
\text { disorders }\end{array}$ & 8 & 8.0 \\
\hline $\begin{array}{l}\text { meconium } \\
\text { aspiration } \\
\text { syndrome }\end{array}$ & 10 & 10.0 \\
\hline Total & 100 & 00.0 \\
\hline
\end{tabular}

Table (5) show the incidence of complication in neonatal, it was found that $57.0 \%$ of cases had no complication, while the other $43 \%$ had complications as shown in table (5).

Table (6): Cut off value and the specificity and sensitivity of $\mathrm{HC}$ in detect the mode of delivery

\begin{tabular}{||c|c|c|c|c|c|c|}
\hline Area under the curve & Cut off value & Sensitivity & Specificity & PPV & NPV & Accuracy \\
\hline 1.00 & 34.6 & 87.5 & 100.0 & 90.0 & 100.0 & 88.0 \\
\hline
\end{tabular}

Table (6), show the cut off value of head circumference to predict the mode of delivery, at $34.6 \mathrm{~cm}$ the sensitivity in detect the CS delivery was $87.5 \%$ and the specificity was $100.0 \%$, the positive predictive value was $90.0 \%$ and the negative predictive value was 100.0 , the accuracy was $88.0 \%$.

Table (7): Cut off value and the specificity and sensitivity of estimated fetal weight in detect the mode of delivery

\begin{tabular}{|c|c|c|c|c|c|c|}
\hline Area under the curve & Cut off value & Sensitivity & Specificity & PPV & NPV & Accuracy \\
\hline 1.000 & 3410.0 & 78.1 & 100.0 & 75.0 & 100.0 & 80.0 \\
\hline
\end{tabular}

Table (7), show the cut off value of fetal weight to predict the mode of delivery, at 3410.0 gm the sensitivity in detect the CS delivery was $78.1 \%$ and the specificity was $100.0 \%$, the positive predictive value was $75.0 \%$ and the negative predictive value was 100.0 , the accuracy was $80.0 \%$.

Table (8): Correlations between the different studied parameters

\begin{tabular}{|c|c|c|c|c|c|c|}
\hline & & Age & GA & BMI & $\begin{array}{l}\text { Intrapartum Head } \\
\text { circumference }(\mathrm{cm})\end{array}$ & $\begin{array}{c}\text { Estimated } \\
\text { fetal weight }\end{array}$ \\
\hline \multirow[t]{2}{*}{ Age } & $\mathrm{R}$ & 1 & -.143 & .097 & .116 & .112 \\
\hline & $\mathrm{P}$ & & .155 & .339 & .250 & .266 \\
\hline \multirow[t]{2}{*}{ GA } & $\mathrm{R}$ & -.143 & 1 & .122 & .069 & .067 \\
\hline & $P$ & .155 & & .228 & .495 & .506 \\
\hline \multirow[t]{2}{*}{ BMI } & $\mathrm{R}$ & .097 & .122 & 1 & $.862^{* * *}$ & $.873^{* *}$ \\
\hline & $\mathrm{P}$ & .339 & .228 & & .000 & .000 \\
\hline \multirow{2}{*}{$\begin{array}{l}\text { Intrapartum Head } \\
\text { circumference }(\mathrm{cm})\end{array}$} & $\mathrm{R}$ & .116 & .069 & $.862^{* *}$ & 1 & $995^{* *}$ \\
\hline & $\mathrm{P}$ & .250 & .495 & .000 & & .000 \\
\hline \multirow{2}{*}{$\begin{array}{l}\text { estimated fetal } \\
\text { weight }\end{array}$} & $\mathrm{R}$ & .112 & .067 & $.873^{* *}$ & $.995^{* *}$ & 1 \\
\hline & $\mathrm{P}$ & .266 & .506 & .000 & .000 & \\
\hline
\end{tabular}

**. Correlation is significant at the 0.01 level (2-tailed).Table (8), show the correlation between different studied parameters, it was found that there was positive significant correlation between mother BMI and fetal inrapartum head circumference $(\mathrm{cm})$ and estimated fetal weight, also there was a significant positive correlation between estimated fetal weight and intrapartum head circumference. 



\section{DISCUSSION}

Prolonged second stage of labor should be determined when the second stage of labor exceeds 3 hours if regional anesthesia is administered or 2 hours in the absence of regional anesthesia for nulliparous. In multiparous women, this diagnosis can be done if the second stage of labor is more than 2 hours with regional anesthesia or 1 hour without regional anesthesia ${ }^{(11)}$.

In modern obstetrics where continuous electronic fetal heart monitoring is available, it's accepted to extend the limit of second stage of labor beyond an hour if there is hope of progress; mother and baby are in good condition ${ }^{(11)}$.

Complicated labor is associated with maternal and fetal morbidity including postpartum hemorrhage, infection (chorioamnionitis, endometritis, and urinary tract infections), severe obstetric lacerations, and postpartum voiding difficulty, while fetal morbidity associated with increase scalp trauma and tends towards increased admission to special care baby unit following instrumental vaginal delivery. Also prolonged labor is associated with increasing rate of operative delivery (primary cesarean section, vacuum assisted and forceps-assisted vaginal delivery) ${ }^{(\mathbf{1 2})}$.

A growing body of knowledge is accumulating regarding true intrapartum ultrasound, a relatively new application of ultrasound ${ }^{(13)}$.

Intrapartum ultrasonography has enabled further understanding of the complex physiology of labor. It has been shown to provide objective data on the dynamics of various stages of labor, and has also been used to determine the prognosis for operative vaginal delivery (14).

In the present study we used intrapartum fetal head circumference and fetal weight as a part of intrapartum ultrasound to predict labor outcome. The present study is a prospective study which was carried out in the period between April 2018 and December 2018. It was conducted on 100 primigravidas who attended the labor ward in Alexandria police Hospital with cephalic presentation suitable for vaginal delivery (no contraindication).

Our study is different from a study conducted by Mujugira et al..$^{(10)}$ that was a retrospective study from population-based study using birth certificate data from the Washington State Department of Health for infants born between 2003 and 2009 of 21,500 full term singleton nulliparous. They measured the head circumference within minutes of birth and assessed its predictive value on labor outcome. Infants with large FHC (37-41 CM) had 2.28-fold (95\% confidence interval [CI]: 1.99, (R.R):2.61 increased risk of primary cesarean section, so the head circumference was a good predictor forincidence of primary caesarian section.

The present study assessed ultrasonographically the head circumference and fetal weight as predictive values on labor outcome. The receiver operator curve
(ROC) showed that these were good predictors of mode of delivery (sensitivity of $85 \%$ and specificity of 92.6 $\%)$. Mujugira et al. ${ }^{\left({ }^{(10)}\right.}$ concluded that there is increased risk of low Apgar score in infants with large FHC with a borderline statistical significance (RR 1.61; 95\% CI: $1.00,2.57)$.They observed no difference in risk of fetal distress (RR 1.06; 95\% CI: 0.95, 1.18) according to FHC. They did not find evidence that the association between large FHC and these two outcomes (fetal distress and low Apgar score) was modified by infant sex (test of homogeneity, $\mathrm{p}=0.69$ and 0.32 , respectively).

In the present study the result showed that mean values of postpartum head circumference, birth weight, and gestational age were $35.2 \mathrm{~cm}, 3598.6 \mathrm{~kg}, 39.03$ weeks respectively, with cesarean delivery rate is $15.9 \%$ with small fetal head circumference (below $35 \mathrm{~cm})$ and $74.5 \%$ with large fetal head circumference (above $35 \mathrm{~cm}$ ).

This is in agreement with Calder et al. ${ }^{(15)}$ who concluded that the mean values of post-partum head circumference, birth weight and gestational age were $34.8 \mathrm{~cm}, 3.2 \mathrm{~kg}, 39.5$ weeks respectively. The cesarean delivery rate was $13.3 \%$ with small fetal head circumference $($ less than $37 \mathrm{~cm}$ ) and $66.6 \%$ with large fetal head circumference (more than $37 \mathrm{~cm}$ ). It was a prospective study conducted between January and December 1999 at the university College Hospital at all term singleton cephalic deliveries, but uses postnatal measurements of head circumference on the second day of live it shows $37 \mathrm{~cm}$ is cut-off value.

Elvander et $\boldsymbol{a l} .{ }^{(\mathbf{1 2})}$ conducted a population-based register study on 265456 singleton neonates born to nulliparous women at term between 1999 and 2008 in Sweden, they used data from the Swedish Medical Birth Register to study the association between postnatal head circumference and the occurrence of the three main indications for instrumental delivery, namely prolonged labor, signs of fetal distress and maternal distress. The authors used in that statistical work odd ratio and Confidence Interval in addition it was which was retrospective study conducted from population-based study using birth certificate data from the Washington State Department of Health for infants but this study use t test and chi-square.

In our study the cut off value of fetal weight to predict the mode of delivery, at $3410.0 \mathrm{gm}$ the sensitivity in detect the CS delivery was $78.1 \%$ and the specificity was $100.0 \%$, the positive predictive value was $75.0 \%$ and the negative predictive value was 100.0 , the accuracy was $80.0 \%$, and there is a significant increase in the incidence of caesarian section with increase fetal weight above cut off value by $62.7 \%$ ( $\mathrm{p}=0.0001)$.

As regard fetal outcomes, $17.6 \%$ of neonates above the cut off value were admitted to neonatal ICU, as regard fetal complications $15.7 \%$ of neonates above the cut off 
value had metabolic disorders, $19.6 \%$ had meconium aspiration, $15.7 \%$ had birth injuries $(\mathrm{p}=0.0001)$.

It is clear that the previous studies work on postpartum head circumference (HC) and fetal weight due to many reasons, from which its essay measurement and it can be measured by either midwife or pediatrician but our study work on ultrasonographic head circumference and fetal weight so we work to have a relation between the two. In our study the result shows the mean of sono graphic head circumference (33.61) was lower than postnatal head circumference (34.35). This tendency for sonographic underestimation of $\mathrm{HC}$ persisted throughout gestation, and become more pronounced as gestation age increased, reaching a mean difference of $(10.5 \mathrm{~mm})$ about nearly. There is a high correlation between the sonographic and postnatal measurement of $\mathrm{HC}$ $(\mathrm{r}=0.963, \mathrm{p}=<0.001)$ this similar to study by Kurniawan et al. (16) who showed the mean of sonographic head circumference was lower than postnatal head circumference. Mean difference between the sonographic and postnatal of $(14.4 \mathrm{~mm})$. There is a high correlation between the sonographic and postnatal measurement of $\mathrm{HC}(\mathrm{r}=\mathrm{o} .845, \mathrm{p}<0.001)$.

\section{CONCLUSION}

The numerical data have a significant relation between intra partum head circumference and fetal weight relative to maternal pelvic diameter and the incidence of primary caesarian section, maternal and fetal complications. So measurement of intrapartum head circumference and fetal weight are good predictors of labor outcome.

\section{RECOMMENDATIONS}

According to numerical results obtained from this study. The study recommends strict labor monitoring by partogram in cases where fetal head circumference is more than $34.6 \mathrm{~cm}$ or fetal weight is more than $3410 \mathrm{gms}$ as these values represent the cut off values above which there is increased incidence of maternal and fetal complications and these values relative to maternal pelvic diameter.

\section{REFERENCES}

1. Calder A (2007): Normal labour Dewhurst's textbook of obstetrics and gynaecology. 7th ed. London: Blackwell Publishing.

2. Konje JC and Ladipo OA (2000): Nutrition and obstructed labor. Am J Clin Nutr., 72:2915-2975.
3. Ekele B and Otubu J (2006): Maternal and perinatal mortality. In Textbook of Obstetrics and Gynecology for Medical Student, Agboola A, Ed, Heinemann Educational Books, Ibadan, Nigeria, 2nd edition.

4. Ugwu EO, Udealor PC, Dim CC et al. (2014): Accuracy of clinical and ultrasound estimation of fetal weight in predicting actual birth weight in Enugu, Southeastern Nigeria. Nigerian Journal of Clinical Practice, 17: 270-275.

5. Kehinde OA, Njokanma OF and Olanrewaju DM (2013): Parental socioeconomic status and birth weight distribution of Nigerian term newborn babies. Nigerian Journal of Paediatrics, 40(3): 299-302.

6. Westerway SC (2012): Estimating fetal weight for best clinical outcome. Australian Journal of Ultrasound in Medicine, 15(1):13-17.

7. Dückelmann AM, Michaelis SA, Bamberg C et al. (2011): Impact of intrapartal ultrasound to assess fetal head position and station on the type of obstetrical interventions at full cervical dilatation. J Matern Fetal Neonatal Med., 25 (5):484-488.

8. Hadlock FP, Harrist RB, Sharman RS et al. (1985): Estimation of fetal weight with the use of head, body, and femur measurements: a prospective study. Am J Obstet Gynecol., 151:333-337.

9. Chitty LS, Altman DG, Henderson A et al. (1994): Charts of fetal size, 2: head measurements. Br J Obstet Gynaecol., 101: 35-43.

10. Mujugira A, Osoti A, Deya R et al. (2013): Fetal head circumference, operative delivery, and fetal outcomes: a multi-ethnic population-based cohort study. BMC Pregnancy Childbirth,13:106.

11. Cunningham FG, Levenokj, Bloom SL et al. (2010): William obstetrics. $23^{\text {rd }}$ edition London. https://www.amazon.com/Williams-Obstetrics-23rd-F-

Cunningham/dp/ 0071497013

12. Elvander C, HOgoerg $U$ and Ekeus C (2012): The influence of fetal head circumference on labor outcome: abased population study. Acta Obstet Gynecol Scand., 91 (4):470-475.

13.Akmal S and Nicolaides KH (2004): Intrapartum sonography to determine fetal occipital position: interobserver agreement. Ultrasound Obestet Gyencol., 24:421-424.

14. Dietz HP (2005): Measuring engagement of the fetal head: validity and reproducibility of anew ultrasound technique. Ultrasound Obstet Gynecol., 25(2):165-8.

15. Calder AA and Edmond DK (1999): Dewhursts textbook of obstetrics and gynaecology for postgraduates. Black well, Oxford.

16. Kurniawan YS, Deter RL and Visser GH (1995): Predicting head circumference at brith: a study in a Dutch population using the rossavik growth models. Ultrasound, 5:123-128. 